\title{
How Generative Mindfulness Can Contribute to Inclusive Workplaces
}

\author{
Kathryn Goldman Schuyler ${ }^{1}$ (D) $\cdot$ Lemuel Warren Watson $^{2}$ (D) Elizabeth King $^{3}$ (D)
}

Received: 9 July 2021 / Accepted: 20 November 2021 / Published online: 14 December 2021

(c) The Author(s), under exclusive licence to Springer Nature Switzerland AG 2021

\begin{abstract}
Humanistic management and mindfulness practices can potentiate one another to foster an inclusive society. By moving beyond a limited instrumental understanding of mindfulness practice to a generative mindfulness that incorporates a recognition of the rich nature of the human mind, awareness of cultural practices, and deeply rooted ethical foundations, managers can create organizational cultures that honor the sacred in every human being. A set of interviews with noted consultants and researchers on mindfulness and leadership suggests convergence on this perspective, as does the experience of a university administrator in developing an anti-racist agenda for a large U.S. university. This article is based on both the personal experience and scholarly research of its authors and suggests ways that humanistic management education can contribute to creating inclusive workplaces through incorporating generative mindfulness in executive development as well as undergraduate programs.
\end{abstract}

Keywords Generative mindfulness · Leadership · Inclusion · Humanistic management · Anti-racism · Action research

\section{Introduction}

How can people live harmoniously with one another, despite what separates us culturally, racially, and economically? In this article, we describe how mindfulness can be a core contributor in creating communities and societies where people feel sufficiently at home with themselves, their beliefs, and their traditions so that they can live and work alongside

Kathryn Goldman Schuyler

kathryn@coherentchange.com

Lemuel Warren Watson

watsonlw@iu.edu

Elizabeth King

e.king@sydney.edu.au

1 Alliant International University, San Francisco, CA, USA

2 Indiana University, Bloomington, IN, USA

3 University of Sydney, Sydney, AU, Australia 
people from very different cultures. Because there are different perspectives in the public, social scientific, and meditation practitioner worlds regarding the meaning of mindfulness, our basic definition of this term is intentionally general. We refer to awareness practices from many different cultural traditions that calm the noisy chatter in the mind, helping one to be present in the moment. There are very precise definitions within the various cultural traditions; we intend this broader meaning. Mindfulness is often defined as being either a state or trait, but for our purposes, arguments about that are not relevant: We are focusing on it as a practice that one learns, and which, after learning, ideally happens both in formal sessions and informal moments, throughout the workday. We perceive humanistic management as a key element in this possible future: one that moves toward an inclusive society grounded in appreciating the inherent worth of all sentient beings. This perspective developed as we explored two fundamental questions:

- How might the practice of mindfulness nourish the capacity to form community across national, cultural, class, and racial divides and generate societies in which all thrive?

- In what ways can leadership and management education contribute to this capacity becoming a central aspect of organizations worldwide?

To enable appreciation of our different voices, we begin by introducing ourselves. Kathryn Goldman Schuyler is an author and professor/consultant of organization development and leadership who has focused on the importance of inner development in creating healthy organizations for a healthy world, with particular interest in contributions from Tibetan and Vajrayana Buddhist cultural perspectives. In addition to being a graduate professor, Goldman Schuyler is a longtime somatic educator, trained in one of the most subtle and sophisticated models of learning from ourselves as sensing, moving systems (the Feldenkrais Method of Somatic Awareness), so she is accustomed to learning processes that are grounded in sensing how one moves, with touch as integral to learning and welcomed-a perspective that is distinctly different from what is typical in university education. Lemuel Watson is an author, professor, researcher, poet, minister, certified mindfulness teacher, and university administrator. His research centers around minoritized populations, leadership, and higher education challenges. Watson's role as a high-level university administrator means that he constantly has to test the feasibility of his theorizing in daily life within the organization. As we spoke, we realized that we shared a wish to shift the discourse from a utilitarian understanding of mindfulness in the workplace to one that is simple and inclusive, fed by both scientific and spiritual sources, and that aims to be transformative at societal levels. Elizabeth King is an author, researcher, and consultant on leading in complexity who has developed internationally-respected theoretical frameworks for mindfulness in the workplace in Australia. Dr. King has years of corporate management life experience and is Lecturer, Coaching Psychology, at the University of Sydney.

We aim to suggest the fullness of what mindfulness can become as a source of nourishment for leaders and educators when it incorporates what we are calling "generative mindfulness". At present, it is rare for organizations to work with the aspects of mindfulness practice that are grounded in centuries-old wisdom traditions across cultures, because of the intrinsic difficulty of bringing such translucent practices into the worlds of business and academia. We say they are "translucent" to suggest that the core of the practices is that they let light shine through. This is intentionally an evocative term. The business world so values concreteness, doing things quickly that can be measured, that it's very hard to speak to the value of something as simple as being fully present with one's mind and heart, and how this can be understood as a practice at all. Wisdom 
practices exist across indigenous and spiritual traditions around the world throughout history, as we discuss later in this article. We have coined the term generative mindfulness to distinguish the possibilities we will describe for mindfulness to become part of daily work life in ways that support people in being present to themselves, their work, and one another while nourished by their own culture's spiritual traditions.

Like all other aspects of life, any culture's grasp of the meaning and potential of something like mindfulness is inevitably shaped by the norms and habits of mind of the given society. The way we think and respond to ourselves, our families, and the world around us is colored by our culture in ways that are usually invisible to us. This is what is studied by the sociology of knowledge, which is the field within the social sciences that looks at how knowledge is socially constructed. Stating that knowledge is socially constructed means that what seems to be normal and expected changes over time and from one part of the globe to another. Decades ago, scholars in this field like Karl Mannheim (1936, 1952), Peter Berger and Thomas Luckmann (1967), and Lucien Goldmann (1959, 1966) offered insights into the processes by which what people perceive to be real and how they think about it are shaped culturally, without anyone becoming aware that their perspectives and behaviors are being shaped. Only recently have increasing numbers of people around the world begun to notice how such hidden processes maintain belief sets that cause business and commerce to work in ways that are destructive to the health of the planet and to large subsets of people on the earth. One example of this which is relevant to the intent of this article is structural or systemic racism: To those who experience it, it has been very real and obvious for decades. To others living in the same society-the United States-not only has it been invisible, but they believe it does not exist. While mindfulness is practiced at the individual level, what is only now beginning to emerge is a collective consciousness for practices of awareness that make visible how our cultural mental habits sustain mindsets and societal practices that keep racism and climate destruction alive.

We will first address the potential deep interdependence of humanistic management, mindfulness, and inclusion. We will then explore what mindfulness has been, is, and could be, based on Goldman Schuyler's personal and professional experience and research. After this, Watson will elaborate on how mindfulness permeates his work with inclusion in organizations. We close by together suggesting implications for management education that could bring our aspirational future alive.

\section{Humanistic Management, Mindfulness, and Inclusion}

Humanistic management and mindfulness practices that come from longstanding wisdom traditions can reinforce one another in creating genuinely inclusive societies. Here we describe what each of these has been, how past approaches inhibit the possibilities of generating a flourishing world, and how they potentially can contribute to such a world becoming a reality. As managers and meditation (mindfulness) teachers perceive their mutual value, the effect on business, education, and society at large could be considerable. Our perspective is depicted by Fig. 1, in which we compare the current state of management, mindfulness practices, and diversity, along with the potential they have as interdependent transformative forces in society. We see the potential for a shift from an instrumental mindset to one that is more purposive and integrated. 
From

Instrumental, loosely coupled mindset

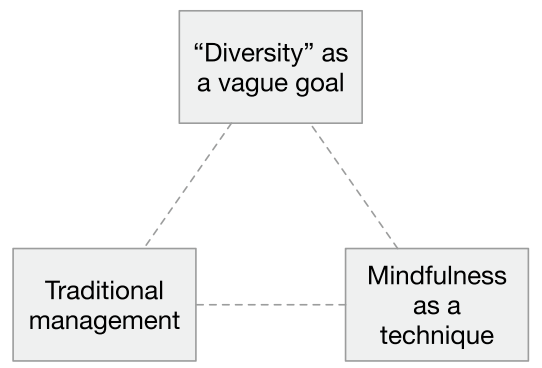

To

Purposive, integrated mindset

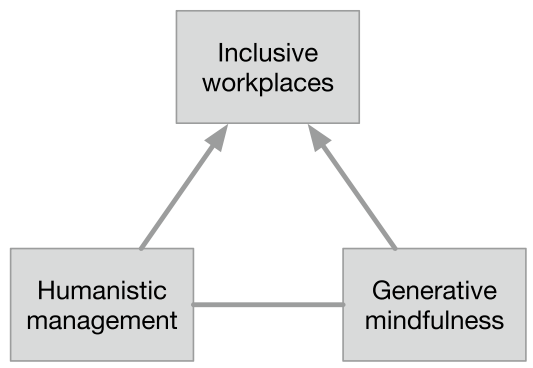

Fig. 1 Towards inclusive workplaces and society

\section{From Management to Humanistic Management}

Historically, management has been defined as getting things done through people, requiring controlling them and measuring outputs tightly. This has enabled human beings to transform the planet for human use, but at the same time, to possibly destroy its potential to support life in the near future (for intriguing discussions of both the creative and destructive impact of management, see George Ritzer 2004a, 2004b; Sandra Waddock and Malcolm McIntosh 2011). Although humanism and humanistic management were intended to create "sustainable human welfare" (http://humanisticmanagement.network/about-us/), as a species we are not there yet. Over the last few centuries, the ways that humanism developed economically involved both species exceptionalism and exploitation of the planet (Laszlo 2019). Humanism emerged in Western European societies during a time when these nations were expanding through colonialism, and the notion of "humanity" didn't include all humans, relegating most who were not white to a lower level of inclusion and participation. The richness of black and indigenous cultures has generally been invisible to "western history."

Pirson and Lawrence (2010), as further articulated in Lawrence and Pirson (2015) theorized how humanistic management can be understood more richly via a renewed Darwinian theory (RD Theory) of human nature and behavior. As they pointed out, most existing models of management behavior are built on mistaken views of Darwin as having promoted the survival of the toughest rather than the survival of the most adaptive. Citing Argyris, Ghoshal, and many other highly regarded management scholars, Pirson and Lawrence (2010) made strong arguments for moving away from an economistic model of human behavior to one that is humanistic and grounded in research showing that most people value leading a meaningful life more than they value money, power, and status (p. 553). Here and in their subsequent article (Lawrence and Pirson 2015), they described how the economistic approach to management emerged historically, how it explicates a very limited view of human behavior as emanating from only two drives (to acquire and to defend what has been acquired), and how humanistic management sees humans from the perspective of four drives (to acquire and defend, and also to socially bond and comprehend what is going on around them). As Pirson (2019) further theorized humanistic management, it can be seen as a means to achieve social welfare, based in dignity, described as "a category for all that is of intrinsic value and which cannot be replaced. That general category can be applied to persons but also to art, heritage, or ecosystems" (p. 42). Here, we focus mainly on the dignity of all human beings as part of an inclusive society. Seeing all humans as 
having dignity can also be expressed as seeing the sacredness of all human beings. As Goldman Schuyler and Watson described this when writing with two indigenous scholars from the Maori and Australian indigenous traditions, leaders who understand beings as sacred.

are people who are committed to connectedness, releasing the potential in others, with an abiding belief in relationships of reciprocity and respect. They inquire bravely into their experience, pursuing journeys of transformation and change no matter how uncomfortable, encouraging others to do so as well in service of collaboratively creating a world where all are respected and valued. (Spiller et al. 2021, p. 82)

\section{From Mindfulness as Technique to Generative Mindfulness as Ethically Grounded Living}

We see a comparable difference between what has emerged over the past twenty years for the understanding and role of what is called "mindfulness", with regard to how it has come to be used in business and what it could become, as suggested in Fig. 1. This will be described more fully in the next portion of this article, but in brief, because of the existing mindset in business of the value of production and outputs, viewing humans through the construct of being "human resources" (Pirson 2019, p. 41), mindfulness practices have been largely put to use to serve business ends within the business context. This has been conceptualized as being an "instrumental" understanding of mindfulness (Badham and King 2021). Strongly critiqued by Purser (2013) and Purser et al. (2018) as "McMindfulness," this refers to the use of meditation practices primarily to calm oneself and manage the stress of work life so as to be more productive, rather than perceiving and drawing upon their potential to deeply enrich a person's understanding of the nature of human and all forms of life.

Instead of being a "technique" or "tool" for stress management, mindfulness practices can serve as what they have been for centuries: the foundations for a way of life that brings humans in touch with their fundamental nature. Such awareness practice enables one to open up to the richness of life itself and of humans as part of this deeply interdependent life process on the planet we call Earth. Historically, this is seen as "waking up," which is a realization that is not limited to one spiritual tradition but seems to live in all or at least many cultures around the globe.

This is also conducive to action for a socially just world-efforts to change those systems that cause the high levels of stress in the workplace, rather than using mindfulness as a technique at the individual level to manage the stress (King and Badham 2020; Purser et al. 2018). Mindful perception does not need to focus merely on personal experiences and self-calming, but can incorporate awareness of the broader world, cultural patterns, and how they are affecting us (Magee 2019). Such generative mindfulness builds on individual awareness practices, so that meditation does not become a pathway to what has in recent years been called "spiritual bypassing": a term coined by John Welwood for using mindfulness practice or meditation to avoid facing developmental issues, rather than to become fully present (Fossella 2011). Instead, we see the development of "generative mindfulness": our term for a process of waking up to one's interconnectedness with all other living beings within the context of culture and society. It is not tied to any particular religious tradition, but instead draws upon what is known across these traditions regarding ways to 
practice that train-or perhaps we might better say entrain the mind and heart to function in coordination, being present to oneself, those around, and the world.

\section{From Diversity to Inclusion}

According to the Society of Human Resource Management (SHRM), inclusion is "the achievement of a work environment in which all individuals are treated fairly and respectfully, have equal access to opportunities and resources and can contribute fully to the organization's success" (Talent Intelligence - https://www.talentintelligence.com/blog/bid/ 377611/inclusion-and-the-benefits-of-diversity-in-the-workplace). Inclusion is the practice of providing everyone with equal access to opportunities and resources. Inclusion efforts in the workplace help to give traditionally marginalized groups (like those based on gender, race, and physical or mental disabilities) a means for them to be equal. This distinction and possible shift is suggested by Fig. 1.

In U.S. society and in many others around the world, inclusion has been very problematic. In the United States, it is still in its early stages, compared to the age of the country. In the period of its founding and for some time thereafter, only males of substantial resources officially mattered and were valued as citizens. Over time, this became racialized. Until the latter years of the 20th century, only those who were considered white as a racial category had such benefits, and others were excluded from equal education, housing, and opportunity. To fully define inclusion, we can draw upon Pirson's (2019) work with human dignity: There is a specific dignity of human beings to be recognized. "Throughout times, from antiquity to modernity, human nature has been considered of special value" (p. 42). Facing U.S. history, we must confront the fact that enslaved individuals were treated as if they had no sacredness, no dignity, and were not humans by much of the country and government. However, despite the thirteenth, fourteenth, and fifteenth amendments to the U.S. Constitution, known as the Civil War Amendments (which created an inclusionary legalistic affirmation that opened access to equality for people of African descent), as we know other means were found to impede such full inclusion.

Equally important to note is that diversity and inclusion are not the same. Diversity is the presence of differences within an organizational workplace or any setting. In the workplace, diversity can mean differences in race, ethnicity, gender, or any other number of things. Inclusion is the practice of committing to ensuring that people feel a sense of belonging and support from the organization. Inclusion in the workplace is about respect: Making sure everybody's voices and opinions are heard and carefully considered is vital in creating an inclusive work environment where everyone is and feels respected. Creating a work environment where everyone feels accepted and all are part of the decision-making process is incredibly challenging and does not happen without consistent support and repeatedly renewed vision and effort.

\section{Moving From an Instrumental to a Purposive Mindset}

We sense that during the challenging period of the global covid-19 pandemic and the response to the murder of George Floyd in the United States in the spring of 2020, a new mindset and collective consciousness began to emerge regarding the value and sacredness of all human beings. Developing leaders who know how to create environments of belonging and who understand individuals as sacred and unique is a core challenge for 
management development, if the United States and other nations wish to create an inclusive society.

Although traditional management, mindfulness, and diversity have been valuable over the past 20-30 years, we foresee that evolving our notions of the nature of these three elements and how they can potentiate one another can facilitate the creation of more inclusive societies, as depicted in Fig. 1. Traditional management, with its roots in the interchangeability of one person for another and the elevation of the value of money over that of human life, increasingly needs to evolve into humanistic management that honors the sacredness or dignity of human (and perhaps all) life. A utilitarian, technique-oriented understanding of mindfulness practices can evolve into a generative mindfulness in which such practices inherently incorporate ethics, compassion, and an appreciation for life itself. Together they can, through their interaction, deepen and enrich people's appreciation for inclusion in society.

Management can evolve from an emphasis on mere controlling and getting tasks done through people, envisioning goals together that make possible an inclusive society on a healthy planet to managing in order to accomplish these while enabling all humans to benefit. Mindfulness can shift from being seen as a technique to manage the stress generated by traditional management and perform better to being seen as practices that enable one to see the full humanness of oneself and others - to be present in the moment with ease and appreciate oneself, others, and life - and thereby be in a good state to get work done. Inclusion then shifts from being one among a set of policies or a "box to be checked" when doing public relations for an organization, to becoming the core principle underlying how they operate. Since Pirson (2017, 2019), Laszlo (2019) and others have quite thoroughly articulated the nature of humanistic management, here we will discuss the other two elements: mindfulness and inclusion.

\section{Exploring Mindfulness Practices as Core Competencies for Humanistic Management}

We believe that mindfulness as learned in most business settings today can be seen as a gateway practice for leadership in a context of a truly inclusive society. By a "gateway practice", we mean practices that are essential for taking steps in the journey toward being a wise leader, but that do not imply one will necessarily be able to draw upon them to transform an organization or society. On the other hand, when mindfulness is grounded or nourished by wisdom traditions - living spiritual traditions that have existed in varied forms in disparate cultures throughout history (for example - Asian, African, Native American, and Maori), it can become generative mindfulness. These wisdom traditions pass down practices for personal experiential learning about how to live meaningfully in community with others from one realized being to others. Such generative mindfulness is not merely a set of practical tools for functioning "better"; it involves practices that over time shift our natural reactivity, so in the midst of the busy-ness of business, we can pause, be present, and remember that both we and all the others in a workplace or global organization and beyond are human beings - all of us with inherent dignity and value. While mindfulness trainers increasingly ground their teaching in the neurosciences, this often yields a functional, individualistic perspective and misses insights from indigenous and wisdom traditions about the interconnectedness of life (Nelson 2016, Spiller 2021). 
Mindfulness, as a set of practices and a view to carry through daily life, can contribute significantly to managing in a human way that includes all people — and all beings and the planet. Looking at data readily available on the internet, "globally between 200 and 500 million people meditate," and meditation is referred to as a "market" that will reach $\$ 2$ billion in 2022 (https://www.thegoodbody.com/meditation-statistics/). The data compiled on this site suggest that $52 \%$ of U.S. employers offered their employees mindfulness training as of 2018 , and the 10 most popular meditation apps generated $\$ 195$ million in 2019. Mindfulness can be seen as a meta-skill that can "enable leaders to continuously develop themselves" (Reitz et al. 2020, p. 224) in order to lead in today's complex world. This recent review of the literature concluded that both training and consistent practice are important in developing this meta-skill. After study and with ongoing practice, it "naturally occurs in everyday life whenever a person is aware of present moment experiences" (Reitz et al. 2020, p. 224). Although it has become popular to affirm that mindfulness training benefits leaders and managers, as recently as 2020, there were few studies that seriously researched the impact of such training on leaders' effectiveness (King and Badham 2018, Reitz et al 2020).

As is not surprising if we look at society through the lens of the sociology of knowledge, the development of mindfulness in business and organizations was unintentionally colored by the capitalist frame in which it has occurred (Purser 2013). Mindfulness has tended to be offered in workplaces as an instrumental training tool for employees to better serve organizations and survive the pressures of work, rather than for what (from our years of study and practice) it has always been at its core: a spiritual journey that enables one to live better in the world through self-transcendence and a sense of interconnectedness with all that is (Badham and King 2021, King and Badham 2020).

We propose a need for learning of mindfulness that roots it in creative, ethical, and emotional learning as practical experience, moving toward an integrated approach to management as a person-centered practice and ultimately placing this in the context of how it can contribute to leadership for planetary sustainability. This perspective is new to humanistic management, as Laszlo (2019) pointed out in his discussion of transitions in worldviews at a global level throughout history. We concur with his incorporation of Otto Scharmer's $(2009,2018)$ presencing (developed with Senge et al. (2005)) as a way to make "direct-intuitive (mindful and spiritual) practices" central to humanistic management. However, considering worldviews (Weltanschauung) as Mannheim (1936, 1952) and other sociologists of knowledge have done, such views imply a broad sense of how life is experienced in different cultures and times. Such worldviews do not specifically focus on management, as they do in Laszlo's description; for example, there are quite sophisticated and subtle understandings of the interconnectedness of life in indigenous and Buddhist views (Goodchild et al. 2021). In fact, Goldman Schuyler (2012) initially became interested in Tibetan Buddhism because she saw it as an alternative worldview to that of the dominant materialist weltanschauung of the social sciences for framing global policy options. We sense that in leaving out the views of indigenous peoples who were more connected with the planet as a living organism (Nelson 2016), believing instead that science had to imply a clockwork-type universe, Western humanism missed some of what makes the very humans it values unique. We try to explore mindfulness as part of this rich tissue of life, intentionally including its spiritual roots, rather than believing that work and organizations must exclude this in order to function well in contemporary society.

Looking at the term mindfulness in the context of changing worldviews over time and space, it's important to recognize the very different worldviews where this term was conceived and lived. In the Tibetan wisdom traditions, "mind" does not reside in the brain or 
head and is not a thing, not an entity, as it is often regarded in the Western worldview. The Tibetan Buddhist view of mind is "less of a specific object than of a capacity to recognize and reflect on our experiences" and "a perpetually unfolding experience" (Mingyur Rinpoche 2007, pp. 41-42). In this world, "The key-the how of Buddhist practice-lies in learning to simply rest in a bare awareness of thoughts, feelings, and perceptions as they occur. ...this gentle awareness is known as mindfulness, which, in turn, is simply resting in the mind's natural clarity" (Mingyur Rinpoche 2007, p. 43). The practice of mindfulness over time allows one to calm the quick reactive patterns of the mind and open oneself to a sense of interconnection with other beings and life itself.

In the next sections we suggest a trajectory for the development of mindfulness in workplaces that draws upon our own spiritual practices as well as upon scientific research, that acknowledges the importance of listening to our hearts so as to include all, and finally supports the formation of healthy communities and inclusive societies.

\section{Kathryn: Reflections with Leaders About Mindfulness Yesterday, Today, and Tomorrow}

Much has changed with regard to the accessibility of mindfulness for Westerners over the last 30 years. We will trace this as seen through my eyes, including the perspectives of some experts in the field that I interviewed in 2020, and close this section with what could be with regard to mindfulness in society.

\section{Yesterday - A Pursuit on the Fringe}

In the 1970s, many in the worlds we lived in believed that society needed a dramatic shift in consciousness if it was to survive, although perhaps Millennials and GenZ members would be surprised to hear that we understood this 50 years ago! We expected that at some point in the coming decades, we would have to face and lead in a world that was sinking into overpopulation, pollution, and mismanagement of resources. Those were not then widely acknowledged as global memes, the way they are today; we were on the fringe, trying to figure out how small numbers of people could leverage societal change for humanity to avoid this darkening path.

Mindfulness per se was unknown as a term. It existed then where it had for centuries: within Buddhist practice, before Jon Kabat Zinn (2011) found it and crafted ways to distill it from its historical roots and embed it in stress management and cancer treatment programs around the world. There were literally no research studies on its potential role for transforming business or society (for a recent contrasting perspective, see the British Parliament study of its potential for society as a whole, Mindful Nation 2015). Movies exploring changing consciousness, like Altered States (1980), considered odd transformations of humans into animals. Although in the 1930s, movies like Lost Horizons (1937) presented imaginary formulations of meditative journeys that had the potential to transform the world for the better, they existed far away, on the other side of the planet, in places none of us expected to travel to. It was thought of as an exotic and mystical process, often aided in the West by explorations of psychedelic drugs. Meditation was taught by teachers from cultures in the East of varied traditions, whether Hindu, Buddhist, or other. One had to be courageous to follow these paths openly-willing to be treated as somewhat odd or eccentric-or else figure out how to make them legitimate, as Kabat Zinn has done so effectively. 
Today's well-known Western teachers had to travel to India or other Asian countries to study, although the Zen tradition began developing Western teachers earlier than most, with considerable interest in it in the 1950s, the formation of the San Francisco Zen Center in 1962, and Zen centers developing in other U.S. cities that have continued until the present day as well. These early students became university professors (like Robert Thurman and Judith Simmer Brown), founders of institutions like the Insight Meditation Society (I.M.S.) in Massachusetts that have strongly influenced the emergence of mindfulness and meditation training (Sharon Salzberg, Joseph Goldstein, and Jack Kornfield), and less well-known translators who made it possible for large numbers of people to have access to writings that were previously available only to very few students (like Jeffrey Hopkins and members of the Nalanda Translation Committee, established in the United States in 1975 by Chogyam Trungpa Rinpoche).

Gradually the presence and influence of mindfulness as a term and a process grew, largely within clinical psychology. Research studies were focused at the individual level, mainly in clinical contexts, and went from a short period in the 1970s where there about 200/year to under 100/year in the 1980s, to a sharp curve upward from the 1990s to today, when they average over 1000/year (https://www.brown.edu/news/2017-10-10/mindfulnessmeditation).

\section{Today - Mainstream Apps and Training}

The public face of mindfulness at work is that it is expanding rapidly, with dramatically increasing numbers of news and research articles and books, as described above. I wanted to get behind this public face by talking to colleagues who have created and/or work in this field, to see what they perceive to be happening. In the spring of 2020, I conducted interviews with people who are either consultants or researchers or both who are very experienced with mindfulness. This wasn't intended to generate statistics, but rather to see what was happening through the eyes of people whose work in this field I respect. They were consultative, conversational interviews done for awareness-based action research on the field we work in. All were willing to be quoted for publication. These interviews were not intended to become a formal qualitative study but rather were structured, yet free-wheeling conversations designed to let me discern what was on the minds of these experts about the state of mindfulness in organizations.

All agreed that it is difficult to form reliable conclusions about the current state of mindfulness practices in organizations, as there is no one place that gathers such information. They also agreed that it's become an industry dominated by large players, that those who lead these training organizations have considerable personal practice but do not tend to share their spiritual roots publicly (though most have spiritual roots), and that there are few corporations that integrate awareness practice into how they run the organization-with an interesting exception being Enpro Industries ${ }^{1}$. The huge expansion in the business world mainly involves training at an individual level initially focused on stress management, with some companies using organizations like Potential Project, Search Inside Yourself Leadership Institute, and the Institute for Mindful Leadership, and most using online apps such as Headspace or Calm. Few use it as part

\footnotetext{
1 See presentation by Marvin Riley, President and CEO of Enpro Industries, Inc, at the Mindful Leadership Summit, November 16, 2019, Washington, DC.
} 
of organizational culture shaping to support managers and executives in engaging with deeper wisdom development practices.

There's little doubt that calming the mind and relieving stress is beneficial, but as one of my teachers has said, "there's meditation and there's meditation." Many people teaching today in the world of mindfulness have no concept of the deep and subtle levels of awareness that have historically been synonymous with a teacher of meditation. This simply doesn't exist in their world. Whereas in the classical Buddhist sense, one is not considered to be a teacher at all unless one has attained stable realization of fundamental truths about the nature of life, in the business or western arena, teacher certification means going through certain steps of training and being able to perform certain tasks. These two are profoundly different ways of looking at what is needed to teach.

Those interviewed concur with this perspective. Michael Carroll, author of Awake at Work (2006) and The Mindful Leader (2008), was one of the earliest business consultants to drawing on serious experience of Buddhist practice. He's also been an executive in several major companies: American Express, Simon \& Schuster, and Disney, and he now consults with C-Suite executives. As he described his work,

I engage through executive coaching that is an intimate dialogue about training the mind. The way I've been trained is that the transmission of these teachings is a very intimate situation, very personal, very human, and we should be very suspicious of its commoditization. Very suspicious of it, because this is not about becoming some better version of yourself. It's about finally becoming familiar with who you are. And that's a profound activity. And it's not a formula.

Those whose research and teaching focused directly on mindfulness all have a personal practice and regard this as essential if one is going to teach others. Megan Reitz spoke about her practice and its importance. She is Professor of Leadership and Dialogue at Ashridge Executive Education-part of Hult International Business Schooland author of numerous articles on mindfulness and leadership in the Harvard Business Review as well as the book Mind Time, co-authored with Michael Chaskalson (2018).

I had a personal practice before I considered bringing it into the workplace and Ashridge. I couldn't teach or do what I am doing without having a personal practice. That's primarily because of my fundamental belief in first person experience and data. So I have to be practicing and going through all of the trials and tribulations and complexities and wonders in order to be able to teach [about it].

Marc Lesser, Co-Founder of Search Inside Yourself Leadership Institute, author of Seven Practices of a Mindful Leader: Lessons from Google and a Zen Monastery Kitchen (2019), Zen priest, and well-known leadership consultant, also emphasizes the personal quality of transmission that is essential, even in the business setting.

This is really all about how to be a full human being-how to live this human life. And when Zen says it's taught from warm hand to warm hand, it's not kidding. It actually means that we learn presence- We learn non-duality at least in part from our seeing it and feeling it with the person we're with. For me, mindfulness has a very particular non-dual characteristic that to me is the heart of mindfulness, which in the conventional world is often left out.

An important question, if we wish to truly transform workplaces, is what mindfulness (or meditation) can do most powerfully. All of those I spoke with were against 
programmatic solutions and standardized trainings taught by people lacking depth of practice. As Michael Carroll said,

As an HR executive, one tends toward a programmatic solution to an organizational issue. That's just the tendency. I mean "Hey, maybe we could do a three-step mindfulness program!" You know I get it! I've done that a million times with a million topics. I truly do understand why you'd want to do that, and there are ways to do it well. And I hope it goes well for people, and by the way I don't believe what I'm saying is the "right way," there are plenty of ways. But when it comes to introducing meditation in organizational settings, I would invite interest rather than offer programs.

This is similar to what Jonathan Reams, a European executive coach, editor of Integral Review and Associate Professor at the Norwegian University of Science and Technology told me. "The kind of clients that we like to work with are people that are willing to go on a journey. One of my potential clients said, 'We're going to do something different--we don't know what yet'." And Andy Lee, who was Chief Mindfulness Officer at Aetna and who trained before that as an MBSR Instructor, said,

What's happening with mindfulness is consistent with how information is being consumed in our culture more broadly, which is that things are shorter, on demand, and digitally mediated. In some ways things are really changing in a very positive way because mindfulness is becoming more and more accepted. However, I think it's being accepted as something that is a shadow of what it could be.

I think silent meditation is really important. You can't have guidance all the time because then you're following somebody else's script. The point in this is to build self-awareness. And then also these short periods of time .... People don't meditate for half an hour any more or $45 \mathrm{~min}$. They do it for five minutes or $15 \mathrm{~min}$, and they do it with somebody guiding them. I think that saps a lot of the energy. And that's assuming that the guidance is good: If it's not really mindfulness guidance, then you've got a much bigger issue. Some people who teach it don't really understand it at all. They think it's the same as relaxation.

A very direct statement came from Charles Morris, a longtime meditator in the Tibetan tradition as well as an engineer and project manager who designed and led a program called "Mindful Growth" at Microsoft as part of Microsoft's Learning and Development Programs. Morris said,

I talk a lot about being versus doing. Whereas so much of the corporate world is about doing-you learn ways to convince people that you are right-I think really what we need is more awakened leaders, which means that they are putting themselves on a personal internal journey of evolution of consciousness. We're really talking about, and in the middle of, a societal transformation.

In contrast with research that focuses narrowly on mindfulness, one of the more intriguing examples today is what globally respected neuroscientist Richard Davidson and his colleagues at the University of Wisconsin's Center for Healthy Minds are doing. Theirs is one of few university-based centers that draw upon a deep understanding of the further reaches of meditation and combine well-designed research with projects carried out in communities and schools. They have developed what they describe as "a scientific framework for the cultivation of human flourishing" (Presentation given in online workshop April 10, 2021). 
They drew upon research in well-being, contemplative neuroscience, positive psychology, and psychotherapy to build a model with four pillars: Awareness, Connection, Insight, and Purpose (Dahl et al. 2020). This is a skill-based approach that has been tested in school systems and universities, showing powerful early results. Rather than only addressing mindfulness, Davidson, (who was challenged by the Dalai Lama in 2003 to apply what was known about meditation in the field of psychology) because of his own depth of experience and scientific acumen realized the need for a multifaceted learning and development process. He has come to believe that mindfulness is a key factor, but not sufficient on its own: A person needs to be in relation to others-ideally in community-and have a sense of purpose, with sufficient insight to learn from daily experience. The relevance of this to creating inclusive communities seems clear: All four of these pillars would be helpful in developing anti-racist cultures.

Similarly, Megan Reitz and her colleagues defined mindfulness in a way that makes it highly relevant for work with inclusion. As she described her work, it is grounded in her essential interest in "how we meet and encounter one another in organizational systems in particular"-which is fundamental for building inclusion. Her research has focused on speaking truth to power and mindful leading and their interconnections. As she described it, the "big themes were our capacity to be present with one another and our capacity to understand and navigate power and the way that is socially constructed." Both of these, we will see, are critical to the way that Watson works with mindfulness and inclusion in building an anti-racist agenda. As she commented when we spoke,

I'm now really interested in how might we mindfully make different choices around speaking up and especially listening. And disrupt what I call conversational habits... So essentially: how do we mindfully step out of autopilot in order to alter important conversations? ... Mindfulness allows us to open up a pause where we then have choice, and before we didn't have any.

This takes mindfulness out of being an individual practice and into the realm of interaction and groups - which is where inclusion and anti-racism must live. She and co-author Michael Chaskalson (2018) had previously defined mindfulness using the acronym AIM: Allowing, Inquiry, Meta-awareness. They describe these as follows:

1. Allowing - an attitude of kindness and acceptance.

2. Inquiry - a curiosity about your present-moment experience.

3. Meta-awareness - the ability to observe your thoughts, feelings, sensations and impulses as they are happening and see them as temporary and not 'facts'. (p. 4)

As they wrote, "AIM is all about choiceful response rather than choiceless reaction" (p. 12). In other words, they consider at its core that mindfulness encourages pausing to take in new information-which is also key to shifting towards inclusionary policies and actions in organizations.

\section{Tomorrow - Wakefulness}

As Marc Lesser said to me, "At the core, this is about 'What can we do to reduce greed, hate, and division so we don't all kill each other. It's that simple, right?"' Simple? Perhaps. Easy? Not at all. But perhaps we are living at the early stages of a paradigm change, where what is considered "normal" changes dramatically. Following on what Peter Senge (1990) 
did by publishing The Fifth Discipline, perhaps we might build on his understanding of the importance of personal mastery or cultivation. We can, in addition, incorporate Sandra Waddock and Erica Steckler's $(2009,2013)$ fascinating research on awareness practices as "retreats." Waddock interviewed the 24 main founders of the social responsibility movement in business to understand what it was that kept them going for the decades needed to create the institutions that now structure this movement. When Steckler studied the data as well, they found that what sustained these leaders through the decades required to create something new in business were practices involving reflection, awareness, appreciation of beauty and nature-which they called retreats.

This would reframe the broader context within which mindfulness research is a central element. This takes a sociology of consciousness perspective, looking at what is required among leaders of systemic change, and how it needs to be supported by individual practice but also to become systemic in focus, as we have seen with anti-racism and the importance of acknowledging systemic racism.

The potential of today's situation with regard to mindfulness is that it can actually become as ordinary as brushing your teeth. The base level of mindfulness practice that involves calming the mind becomes a fundamental action that most people learn either as children or young adults. Then some, who wish to serve as teachers or leaders, would explore the wisdom aspects (Goldman Schuyler 2016). The retreats that were seen as core to entrepreneurial success by Waddock and Steckler $(2009,2013)$ could become normalized through business school education in humanistic management. What was natural for these innovative leaders could become core to all management learning, so that leaders do not have to withdraw to mountaintops to find spiritual wisdom-as they have done throughout history in the great myths - but can instead learn both management and wisdom skills in graduate business education and be supported in building on this by their boards. Moreover, instead of having to identify and distill the separate sources of spiritual wisdom and contemporary scientific knowledge about planetary sustainability, this can become core to leadership education and development around the world. Many have been writing about "wise leadership" over the past decade; this could now be integrated as a core element in business education, rather than it being perceived as "fringe," as mindfulness was 30 years ago.

The roots for such wisdom exist in many cultures and their spiritualities. They are found in Buddhism, Judaism, African cultures, Maori and other indigenous cultures, Hinduism, and Christianity. Waking up is a metaphor that is used in many Wisdom traditions: It can become a unifying, common thread in humanistic management as well, sourced by the kinds of learning that Senge, Scharmer, Goleman and others have been developing and testing globally. As Senge (2012) said when discussing this question,

Leaders should be people who are deeply involved in their own realization of becoming a human being.... In traditional Chinese culture it's well understood that to be in a position of authority you must be a very advanced cultivator. The old saying was that the Emperor should be the wisest person in the land, and if not, then the Emperor's advisor should be. While that's an ideal that was not always reached, it symbolized an important connection between cultivation and leadership authority. (p. 326)

Although the gap between this possibility and today's realities may seem as large as ever, perhaps the coming together of research and practice in this area will help this potential to emerge. 


\section{Integrating mindful moments into work: A case study}

When we reflect and write about on what we are doing as we explore generative approaches to mindfulness in work settings, we can use what is known as "action research" to open up the possibility of sharing what we learn through experience with others in systematic ways. Action research, developed from Kurt Lewin's social science studies in the 1940s, has been defined as

.... a family of practices of living inquiry that aims, in a great variety of ways, to link practice and ideas in the service of human flourishing. It is not so much a methodology as an orientation to inquiry that seeks to create participative communities of inquiry in which qualities of engagement, curiosity and question posing are brought to bear on significant practical issues. (Reason and Bradbury 2008, p.1)

We believe that action research is invaluable in studying and sharing attempts to develop new patterns of thought and interaction.

As an example of how this can happen within a leadership team, Goldman Schuyler, Taylor, and Wolberger (2018) explored introducing mindfulness into a management team of a 1,000-person Student Affairs organization at a large university. We did this in the context of an action research project, in which Taylor (the V.P. of the organization) invited the members of her team, if they wished, to develop their own ways of bringing mindfulness into their daily work. Taylor led the action, Goldman Schuyler consulted on incorporating mindfulness as part of the organizational culture change she wished to bring about, and Wolberger interviewed the participants as the main researcher. As Wolberger and Goldman Schuyler (2018) described this in a conference presentation to management professors, Taylor was "Leading Change Gently":

Mindfulness most often is brought into the workplace through training to support individual practice, but instead we wanted also to generate a more mindful organizational culture. To describe the process, we applied a framework to understanding change that is based on processual philosophies. In doing so, we hoped to pursue a deeper understanding of the complex nature of change as a state of becoming, which gave us the image of "leading change gently."

Both the action research study on this project and the dissertation addressing it (Wolberger 2018) were grounded in a process view of change, as developed by Chia (2014). Without prompting, as described at length in that article, participants became more aware not just of themselves but of the beauty and vitality of the natural environment around them and most important, gained a renewed sense of the purpose of their work, combined with a renewed appreciation of the people with whom they interacted daily, both at home and at work (Goldman Schuyler et al. 2018). This happened both for the members of this team and also for a global group of consultants and professors who experimented with a similar very open approach to noticing moments of "waking up" as they happened to occur throughout their days (Goldman Schuyler et al. 2017). At the close of the process in the university, many participants spontaneously commented on their experiences and how they had shifted from initial skepticism to enthusiastic participation.

In this context, Lemuel Watson's description of how mindfulness is core to his work as a university administrator charged with coordinating an anti-racist agenda in a 48,000 
student university that is dispersed across nine campuses can also be seen as a rare leadership case study. It is a form of auto-ethnography or first-person action research that shows how mindfulness influences the way he addresses collective issues. We include it here to suggest the ways that leaders can make mindfulness core to their being and leadership actions.

\section{Lemuel: The Language of the Heart - Creating Inclusion in Society and Learning}

As a leader in the university setting, I seek to create the space and place to have open, sincere, and safe conversations about ourselves, our communities, and our world. Acknowledging our collective histories, both the positive and negative, while finding the space to dialogue and celebrate our differences, is no small task in the current environment. How people choose to engage is shaped by their past experiences and the stories that family, friends, and community have shared. All of these influence our thinking and behaviors about how to be with others in this world.

My way of thinking about diversity, equity, and inclusion is to accept that our unique lived experiences are co-created. Our experiences belong not just to us, but to the ancestors who shaped them, the progeny who will inherit them, and the countless others whose lives run parallel to ours. To see how our individual experiences contribute to our shared, co-created experience, we must dialogue with ourselves, each other, our histories, and our futures. This work is intertwined with integrity, respect, and trust-the humanistic values that help us form a community of belonging. To learn, work, and live together, we must see and understand each other's backgrounds and communities, hopes and dreams, fears and joys. We must know and build trust with each other. There is no shortcut. If I understand your journey, and you understand mine, we can co-create solutions to our challenges. When we value multiple perspectives, we create a community that values who we are as individuals - a community, in short, that values our diversity. Warren Bennis (2010) projected the notion that leadership can be no better than our understanding of each other and what motivates our behavior because leadership is about the connections among us and being in relation with others. My goal, therefore, is to help others see that anti-racist work is fundamental in any human-intensive institution, especially an educational organization.

My framework (In process) for change and consideration with integrity, inclusion, and influence captures this visually as an overview for the anti-racist work conducted at the organization (Fig. 2). This shows visually how complex and dynamic the process is for building a community that accepts responsibility to hold itself to the highest integrity toward roles, duties, missions, and goals. Figure 2 demonstrates that adaptive leadership occurs across all levels-self, organization, community, and society-simultaneously within many contexts and across diversity of individuals, while understanding human behavior at the core. For example, understanding, emotional intelligence, organizational justice, innovation, and good character (or, presented in leadership language, systemic, biological, service, and psychosocial perspectives like human resources/talent management) are basic competencies in management and leadership roles.

Ronald Heifetz developed the term adaptive leadership in his seminal book, Leadership Without Easy Answers (1994). In simple terms, adaptive leadership theory focuses on how people in power respond to changing environments, emphasizing the activity of the leader in relation to that of the employees. Gary Yukl and Rubina Mahsud (2010) contended that 


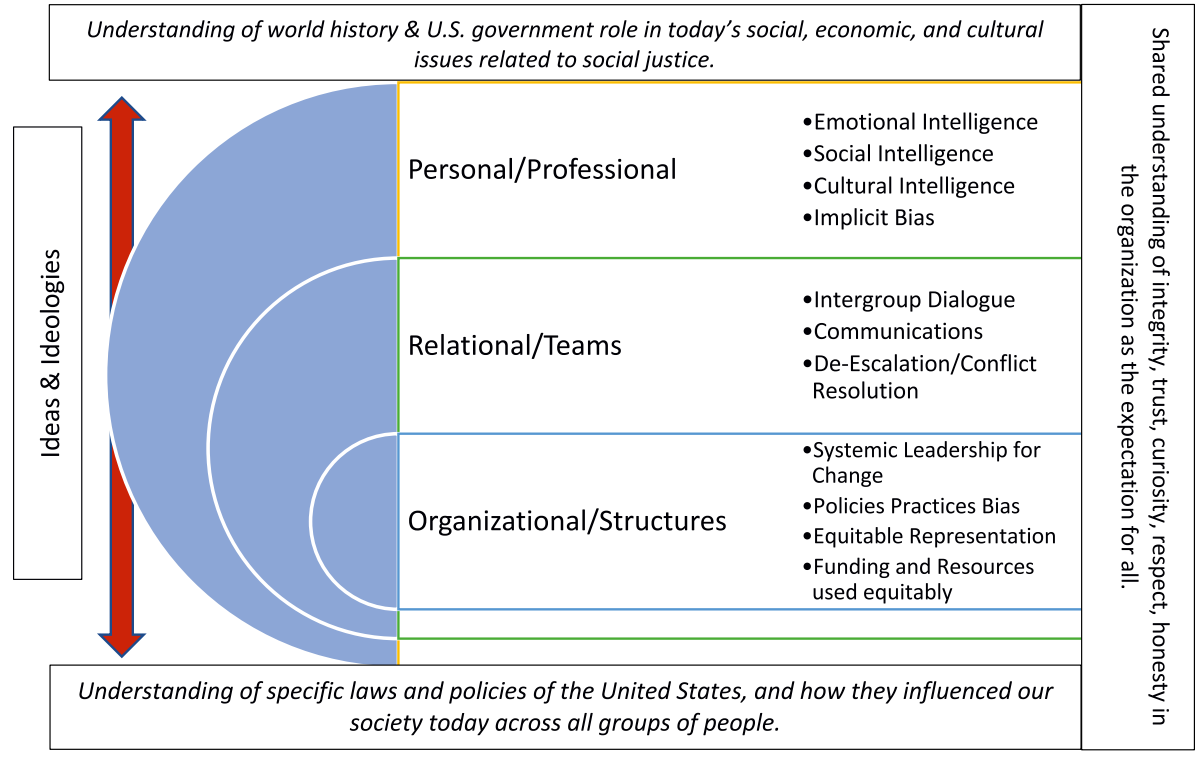

Framework - L. W. Watson (2020)

Fig. 2 Systemic change and consideration with integrity, inclusion, and influence

the need for adaptive leadership grows as the pace of change increases. Most traditional leadership models focus on a leader's specific traits - their authoritativeness or charisma, for example. In this view, the characteristics that define leadership are fixed; one simply either is a leader or one is not. In other words, the traditional model sees leaders as born, not made. Heifetz's view, by contrast, emphasizes not fixed characteristics, but adaptive capacities, focusing on the behaviors of a good leader (Northouse 2016).

Instead of mobilizing followers through fear and respect, an adaptive leader motivates others to "tackle tough challenges and thrive" (Heifetz et al. 2009, p. 14). The adaptive leadership model encourages effective change across multiple levels: self, organization, community, and society. This approach involves diagnosing, interrupting, and innovating to create capabilities that align with the aspirations of an organization.

How does the adaptive leadership model apply to the task of anti-racism? Challenges are difficult to identify and resolve through traditional channels. Since Diversity, Equity, and Inclusion (DEI) work is about ensuring that everyone is included, an institution that is committed to anti-racism must adapt to the appearance of new people, new identities, and new ways of being. An adaptive team understands that because people change, our environments must change with them. When employees are empowered to co-create solutions, they can bring their own unique experiences to the table, ensuring that solutions to problems will work for them and not just for those who have power under the traditional model. There is no way to make powerful, impactful, and sustainable changes with respect to equity and inclusion if we do not systemically address DEI issues through personal, professional, relational, and organizational structures, and strategize with integrity and trust. A leader's actions, disposition, and way of being motivates others to take on leadership roles in their own way. The ability to bring your best authentic self to the work environment is what I also call a "sacred leadership space." I have attempted to suggest this rich complexity and the systemic approach needed in Fig. 2. 
My role as associate vice president coordinating Indiana University's Anti-Racist Agenda involves a process of co-creating lived diverse experiences of building upon the practices, discipline, theories, and engagements necessary to address the hard questions about our "we-ness" in the 21 st century. We want to have inclusive policies, practices, and procedures, along with a structure to hold individuals accountable - and we want it to be sustainable for future generations. Dialogue with ourselves, each other, our histories, and our futures is necessary to embrace the notion of an anti-racist organization. Therefore, being an individual led by appreciation for our collective human spirit, my leadership emerges from within to engage with care, integrity, and responsibility with all I encounter in the workplace.

\section{Diversity and Inclusion as a Natural Expression of Mindfulness}

In this context, my skills in mindfulness practice help me to stay grounded in the present and to offer what is needed as I work with multiple constituents across the university. Mindfulness, awareness, and emotional intelligence skills are tools I draw upon naturally due to years of practice. In formulating my role, I decided to stay detached from immediate outcomes, because changing minds, hearts, and culture takes time. I attempt to be mindful; therefore, I reminded myself to listen and learn and not make assumptions as I began this journey to lead and coordinate university efforts toward being an anti-racist organization. I had trust in the process and in my experience: Over and over, we will strategize together to co-create solutions and activities, to create spaces for courageous dialogues, and to provide opportunities for reflection about our collective work to be accomplished. I am fortunate to have a structure with professionals in DEI-related responsibilities to collaborate with across our nine campuses. Building on their experiences and success enhanced my efforts to coordinate our anti-racist efforts. The university has a history of supporting minoritized populations; it is not a perfect history but a commitment to social justice. Although considerable progress has been made in diversity, equity, and inclusion work, the prevailing practice continues to be that it is peripheral to the core operations of most institutions.

DEI work requires awareness and being mindful of our thoughts and actions as individuals and how they play out with others, how we serve others, how we treat others. This is at the center of serving our communities and constituents. To be generative, diversity, equity, and inclusion work requires serious discussion among those in power about dealing with those human differences that are intertwined with deep-rooted beliefs and values about our collective histories and ways of being (Watson, in progress). Conversations about race can feel too traumatic to address for many in our communities, because they have never had to think from multiple perspectives about themselves and the world (Watson, in progress). Yet, if we are going to move our society and institutions towards excellence, leaders and community members must directly address the things that we have been skirting around for the last seventy years in integrated public organizations. We must bring truth and light to issues of class, racism, power, and white supremacy: the way males of European origin systemically and strategically developed the United States to advantage whites over others.

In our current environment, I remind individuals that we cannot repeat our past practices related to DEI work in general - habits of the past are no longer wise and will not bring us closer to our objectives in the university. Our new reality requires community members and especially leadership to embrace deeper thinking and deeper ways of knowing about DEI issues. For example, when I work with various groups on strategies for solutions, as much as possible, I am fully present and come to each discussion and situation 
without predefined outcomes. I often remind groups that our histories are directly tied to current problems or race and economics. I encourage people to be mindful of their automatic responses and to pause before reacting. More importantly, I challenge them to be curious about why such a response is present and where it was learned. Asking them to pause before reacting while asking "What if I am interpreting something without understanding?" is just one way to bring mindfulness into the consciousness of groups. I encourage everyone I speak with to explore and be curious, because none of this matters if we are not personally committed to our own cultivation, professional development, and engagement in the organization to create a community where all individuals matter.

Therefore, I stress that DEI work of the future is the responsibility of all the university's employees, groups, communities, and networks. We all have voices to be heard and understood with various pasts and backgrounds. One leader, a single office or unit, is not the way forward with the future of DEI: We need individuals who can approach life, work, and responsibility with openness and awareness.

Anti-racism is about the commitment to actively work to call out racism whenever and wherever one finds it. It is about examining the power imbalances between racialized people and non-racialized/white people, which results in unearned privileges that white people benefit from and racialized people do not (McIntosh 1988). Kendi (2019) put forth the perspective that to be an anti-racist individual or institution, one must engage in persistent self-awareness, constant self-criticism, and regular self-examination. This is mindfulness and awareness at its simplest. We examine policies, practices, and procedures for bias language and assumptions across every area of all institutions. We ask ourselves whose perspectives are included and whose are left out of the work we are trying to accomplish as an organization.

\section{Indiana University: Bringing an Anti-Racist Agenda Alive}

The unique perspective that Indiana University has taken is to select someone with the interdisciplinary skillset to work across the institution and across multiple groups to cultivate a pathway to think about this work. It is important that I bring a practice/behavior for modeling how to dialogue, pause, listen, and cultivate members of the community. Indiana University purposefully wanted to identify someone who would be committed daily to thinking about this work, while having the skillset to work across the organization, exploring opportunities and holding discussions about what is possible with DEI. At the core of our anti-racism agenda, we stress that shifting leadership from hierarchies to more distributed decision making is key, in order to respond to diverse constituencies in ways that we have not before. If we reflect on what complex societies need in order to function and flourish, they need people to appreciate the contributions of those who are different, to honor each person, and to have structures that bring people together across their differences.

Helping individuals to understand the meaning of anti-racism, why we embrace building a community of belonging, and why it is everyone's responsibility to be a part of an organization that is moving in this direction has not been difficult when individuals sincerely comprehend our intentions. Having individuals participate in discussions, questions, and strategies for their work environment and the ways of thinking and being that they need to be aware of has been very rewarding in this work. I have not had any significant moments of anger or frustrations in bringing this work into our collective consciousness. I also attempt to peel back all assumptions from the core of what needs to be realized; to make the complicated simple; to use facts and data versus untruths; so that we can truly see 
each other and acknowledge that we are all human with many limitations and gifts, and we can find a way together to create a community of belonging.

With all groups and individuals with whom I met this year, I tried to create a space of safety, trust, and openness about the work that needs to get done, while addressing all specific issues or perceived challenges. My role has been to be the one who thinks about this work daily and keeps us moving forward. As we work to build a community of belonging and an anti-racist organization at Indiana University, I ask, "What if we remember, with each person we meet, that they have unique perceived experiences, and we don't know what those circumstances are or have been?" In today's world, there are so many preferences and ways of being which are not binary but multiple-multiple identities or intersectionalities that are important-we should not make any assumptions about an individual's background or identity until it is shared. In my current role, I often reference the four agreements by Don Miguel Ruiz (1997) to remind individuals of how easy it is to misinterpret others' behaviors and words: I encourage them to be mindful, pause before reacting, and remember we all have value and gifts to offer as humans.

As a leader, I make it a habit to ask each member of my team their perspective on issues and to close meetings by asking each member if they have any final thoughts. This practice helps to make sure that all views are heard and considered during the meeting. In addition, it also conveys to each team member that they are valued. If this is standard practice, each member will know that they matter regardless of gender, race, or ethnicity. As I reflect on the skills needed to thrive in our diverse society today, given the trauma and drama that individuals experience, most of us need to enhance our skillset in mindfulness, emotional, and social intelligence if we are to be more effective with the world's diversity and workforce. In a recent study by Search Inside Yourself Leadership Institute (2020), of 955 global leaders in 59 countries, emotional intelligence was listed by $85 \%$ as an essential skill needed for the future. Self-awareness and self-management are two of the emotional intelligence skills most related to mindfulness.

How then do we invite those who have been left out to join us in a sincere way that changes our work and environment to be inclusive? As a university, we are engaged in bringing this mindset into all of our practices, from recruiting faculty, staff, and students to our partnerships in multiple communities. If we stop and think and acknowledge that while I am here, you are here, and we are together in this place, at this moment, we can also ask whether there is anything we might do together to make life better for us and the world that would mean less suffering. In this context, anti-racism is an act of opening oneself up through self-reflection and self-awareness to the infinite possibilities of sharing humanity with all human beings around the planet. The practice contributes in a tangible way to building community, trust, and openness, because it conveys that other opinions and perspectives matter to us. This brings us full circle back to the importance of mindfulness and spirituality, both of which are essential to our sacredness as humans.

We must remember that leadership is a process of becoming. There is no specific set of strategies for being an effective leader. According to the Paradigm of Cultivation for leadership, people become who they are through their engagement with the world around them (Biesta 2019). This model is reminiscent of John Dewey's (1917) theory of reflective learning. When we reflect on an experience, we learn not only what we did in the past (our histories), but how we might consequently change our future behavior and the world around us. Thus experience is always futural: "What should experience be," Dewey asked, "but a future implicated in a present!" (1917, p.12). Or to think of this another way, how might I be present, silent, gentle and sacred in my role and responsibility as manager and leader? Creating spaces for reflecting on our experiences shapes our future, our 
work environments, and our society. This Deweyan notion is central to anti-racist work and humanistic management. By continually reflecting on constantly changing social environments, we can help to shape them. Lawrence and Pirson (2015) reiterated that "not only is the job of the leader in the twenty-first century much more complex, it also requires much higher levels of political insight and reflective capacity" (p.383).

A reflective leader therefore spends time getting to understand themselves (personal), their workers (the relational), and the organization (structural) while creating an environment where all feel welcome to engage in difficult conversations (as depicted in Fig. 2). Domènec Mele (2003) called such leadership "humanistic management:" that is, leadership that emphasizes human needs and experiences. For Mele, humanistic management requires understanding that the work environment is a real community of persons where unity and favoring the acquisition of human virtues is of the essence. When we do this, we can achieve a higher moral quality within leadership and across organizations. By contrast, individuals who depend on traditional principles of leadership and ignore the changing context of our times face a difficult and uncertain future (Fullan 2006, Fullan and Scott 2009, Schon 1990).

\section{Mindfulness-Based Humanistic Management Education That Moves Society Towards Inclusion}

Many of the practitioners who incorporate mindfulness in leadership development are deeply aware of the fullness of mindfulness practice and of its roots in wisdom traditions around the world. However, on the whole, the leaders of global organizations currently value trainings that resemble simple manufactured products, rather than craft or art cultivated like delicate flowers. Both higher education and business have thick cultures, with ways of functioning and sustaining themselves, so the change is greater than it may seem. Organizations that sincerely want to help employees in a way that also yields a healthy bottom line generally don't perceive how introducing mindfulness may involve more than introducing a new set of actions or practices, but instead mean shifting the underlying viewpoint from which action occurs. The business world is so entrenched in its own cultures, that changing viewpoints, language, and meaning to become truly different is a huge challenge, so introducing mindfulness as simply an individual instrumental practice is not the fault of individuals. Rather, it is almost inevitable in our contemporary societies.

As Swidler (2019) reminds us, the evolution of our human condition is intertwined with various pasts, which points towards a reality that is essential if we are to heal the serious problem that inheres in all aspects of our human cultures and threatens our very survival: namely, the awakening of human beings to genuine dialogue. To foster an organizational culture of true dialogue, leaders must not only embrace emotional intelligence, awareness, and mindfulness but embody it in how they listen and respond, honoring the sacredness in all human beings.

If the United States is to make powerful, impactful, and sustainable changes towards equity and inclusion, we need to address this systemically, as depicted in Fig. 2. The (a) personal/professional, (b) relational, and (c) organizational structures and strategies all must be addressed simultaneously, with integrity and in ways that generate trust. This requires both grassroots and top-level leadership to use a shared language that is easily understood and practiced. Such a holistic, systemic approach can move an organization towards being an anti-racist institution (Watson in process). 
In this context, as educators, we can incorporate generative mindfulness in management learning in ways that fit well with the mindset of humanistic management, that are conducive to removing structural racism, and that enable inclusion. To do so, we will have to be creative, given the skeptical bent of some administrators and faculty colleagues. The strength of academic traditions that divide knowledge into particular fields and only rarely offer immersive programs that might truly transform our hearts and behaviors can also present challenges. Unfortunately, when well-intentioned leadership/management educators wish to bring awareness practice into higher education, it is often treated as a series of practices that can be "pasted into" a curriculum-rather than as a stream of understanding that colors all they do and how they do it. In order to bring generative mindfulness into courses, whether for undergraduates or executives, those introducing it need deep experience themselves. Doing this both in regular coursework and in periodic immersive learning settings makes it likelier to actually influence behavior.

The following are some elements we see for such programs:

- Basic meditation training and practice. Often known as shamatha, there are basic practices for calming the mind so participants are less caught up in their own fears, desires, and projections, and begin to see things more simply, as they are, without webs woven by the mind. This could be framed, as Chaskalson and Reitz (2018) have done in ways that connect such training with communication and action in organizations.

- Relational systems thinking. Understanding oneself, one's society, climate change, and business require strong capacities in systems thinking, not just as an analytical tool about processes in the world, but also as a way of understanding oneself. Although referred to as "thinking", the systems perspective is one that includes the heart: a deep engagement with others and with life (Stroh, 2020). Indigenous perspectives can be incorporated as well, yielding what Goodchild et al. (2021) described as "relational systems thinking".

- Embodied learning.

- Moving with awareness, integrating breathing. Such learning programs can draw upon a combination of yoga-like practices that channel energy and awareness and more active movement that integrates breath and move all parts of the body. This invites flexibility and fluidity, with enhanced awareness of oneself as an embodied being.

- Community-action projects. Simple forms of action research can support students in simultaneously tracking their awareness of themselves in action, being engaged with the complexity of systemic change, and learning how to monitor the effectiveness of such change interactively with others-not attempting to "do change projects" on people, but rather to engage with communities in support of exploring possible changes that they define (Wilson 2016, 2019).

- Peer-co-counseling. Participants learn to look at, reflect on, and tell the stories of their key experiences with change. This makes it possible to be more honest in speaking about oneself, so that rather than trying to cover up weaknesses or problems, one learns to be with them in ways that they begin to change on their own.

- Communication awareness development. Incorporate reflection and discussion of one's way of being in work settings and how it affects people and the process of creating an inclusive workplace. Lead and manage through one's way of being and interacting. Be vulnerable and support this in others. Connect how we communicate with processes 
that develop our awareness of ourselves as embodied beings, whose state of mind automatically affects those we are with.

- We might include questions like -

- What non-verbal messages do I convey when related issues of diversity, inclusions, or equity surface?

- What actions do I take to show these issues are serious and that they matter to work environments, our well-being, all employees, and organizational success? What is my comfort level in discussing these issues?

- Do I give space and place for others to share their discomfort and be vulnerable to learn and engage in developing support of others sincerely?

- Do I have the actual skillset and tools to help the organization reach its potential as a just and anti-racist organization? If not, find the resources needed to build these.

Developing anti-racism in the context of mindfulness means looking for and eliminating false notions of race and racial superiority that linger in society's consciousness that may be embedded in our words and actions. It means actively changing our attitudes, knowledge, dispositions, and behaviors. Leaders should be aware of who is not at the table when strategic decisions are made about the institution. Our mindfulness brings us to pause and ask essential questions about who and how we are, both as individuals and as a society.

\section{Conclusions}

We encourage you to bring attention back to the essence of why you are attracted to mindfulness at all. Generative mindfulness lives as an awareness that brings us closer to understanding ourselves and the world around us, as practices that honor, support, and care for other beings through compassion, and as actions where we offer our wisdom, hands, and hearts to serve one another. Such mindfulness supports us in doing our real job rigorously: being fully present and ensuring that the organization has the talent to continue to manage effectively and efficiently for the future. Mentoring and committing ourselves to the development of future leaders and the team are as important as anything else that we do. From the moment one walks into an organization, professional development for the team should be essential. Our actions, disposition, and just our way of being motivates others to step into a leadership position. Bringing our best authentic selves to the work environment is what creates a sacred leadership space - thereby living in the dynamic that occurs when humanistic management and generative mindfulness work together to create inclusive workplaces.

As we have mentioned, another way to view the challenge of creating inclusive workplaces and societies is through the concept of "presencing" - a systemic way of looking at the processes of learning and change from the perspective of the natural world, where there is an ecological structure and an understanding that the whole is entirely present in any of its parts (Scharmer 2018; Senge et al. 2005). Presencing encourages us to go deeper in our learning to create awareness of the larger whole while acting in the present to shape our future. This is central to the notion of generative mindfulness: being aware, mindful, and informed as we think about the context of our work at personal, relational, and organizational levels. From another perspective, presencing is like being in the flow of things: We are fully present, allowing our experiences, our spirit, and our inner knowledge to align with what is needed from the group or individuals as we do our work to find humane and 
just solutions to multiple challenges. Being open to various realities while interacting with multiple players requires leaders to [1] know themselves enough to understand their own weaknesses and strengths (personal), [2] be knowledgeable about numerous histories and conditions of the past to engage sincerely with diverse populations (relational), and [3] keep the integrity of one's role as part of an organization while identifying barriers that hinder inclusion (organizational).

To accomplish the mission and goals of an institution while leading a diverse group of individuals who see and experience the world differently is a challenge when working with multiple generations, gender identify, race, religion, nationalities, etc., as we work to build collegiality and teams. Using mindfulness and awareness as the avenue for this journey helps one craft bridges to weave together the languages, experiences, and cultures in joining groups of people together. The exchange of ideas, practices, and cultures to ponder and test against our own helps to make us wiser if not better. Becoming "more you" as a leader involves remembering daily that it is a journey which builds confidence, wisdom, and the innate resilience out of challenges against the organization, your leadership, and-what sometimes feels so personal- you as the individual. One must never lose self-respect or composure in a way that is damaging to the point of being ineffective. This is yet another delicate balance of awareness between leading with kindness, sincerity, and fairness, yet strength and conviction, which conveys understanding of the seriousness of position.

We like to champion the notion that our shared humanity is the foundation for understanding and communicating with others. We are first humans and are deserving of respect, care, love, empathy, compassion, and understanding and should be treated as such. If you really don't know me, how can you help me, or serve me? This translates to the conviction that you should not judge me or anyone else based on my outer appearance or shell. We deal with humans who bring their past experiences and lenses to the workplace, which influences what they believe they are seeing and experiencing. It does matter if you are a white man, black woman, or Hispanic: It comes with the territory. Accept it, and just breathe and practice graciousness. This is where dealing with issues of diversity is paramount in the ability to value all and handle conversations that bring challenges but yield transformation if you are wise enough to stay curious throughout the journey —while asking a wise team to help. No one person can or will be enough for a dynamic world, given that our personal, national, and global identities are constantly changing.

These constant changes within a dynamic world and work environment in turn pull upon our overall well-being as leaders. So many leaders are socialized into mindless autopilot responses that do not work when constantly bombarded by the demands of the job and world. Leading requires time to focus and be still within ourselves in order to hear a spirit of discernment for decision making regarding our own actions - which influences everyone else, including the general work environment and culture. Leaders can transform work environments just by walking in the room if they are aware of this presence. The environment picks up on your tensions, energy, and perspectives (Spiller et al. 2021).

Perhaps consider this a call to action for managers in organizations to collaborate with scholars in addressing the real challenges they face, and for scholars to seek organizational contexts to conduct field research on the impact of initiatives intended to foster inclusion. In addition to more traditional survey research and studies that seek to quantify the impact of mindfulness or DEI processes, we suggest that humanistic managers seek to learn from the way they lead through awareness based action research projects that offer a first and second person view into organizational life (Coghlan and Brannick 2001, Goldman Schuyler et al. 2018, Wilson 2021). In this way, we can walk together, co-creating greater 
understanding of the value of generative mindfulness in the context of humanistic management in creating work environments in which all persons can flourish.

In a sense, the movement toward workplaces and societies of inclusion, grounded in the dignity of all human beings and perhaps all sentient beings, marks an evolution in human's self-conceptualization. It suggests a shift from the insights of the founders of sociology about the nature of being in society. They theorized a distinction between those humans who live in urban areas, who become more impersonal and transaction-oriented, and those who live in smaller, more rural communities, whose interactions are more personal (see for example Tönnies (1887/2002) on the distinction between Gemeinschaft and Gesellschaft or community and society). As we look at the forces in today's world and contemplate what we see to be possible, an inclusive society seems to overlay the two types, suggesting the possibility of creating community within complex, urban-based societies. Instead of having to choose between an alienating, impersonal urban environment and a perhaps too-cosy, even claustrophobic small community, through humanistic management and skillful generative mindfulness we foresee inclusive complex workplaces and cultures where people gradually learn to see what we view as the sacredness of all human beings: the ways that we are the same, rather than the superficial differences that so often separate us.

\section{Declarations}

Conflicts of Interest/Competing Interests The authors have no conflicts of interest to declare that are relevant to the content of this article.

Ethics Approval The only portion of this article involving gathering data was conducted by Kathryn Goldman Schuyler. This involved interviews with experts in the field and was granted an exemption by the Alliant International University IRB 08/01/2019 as Protocol \# 1907145279, Mindfulness at Work: The Experiences of Researchers and Practitioners.

\section{References}

Badham, Richard, and Elizabeth King. 2021. Mindfulness at work: A critical re-view. Organization 28: 531-554. https://doi.org/10.1177/1350508419888897.

Bennis, Warren. 2010. Foreword. In Driven to lead: Good, bad, and misguided leadership, ed. Paul Lawrence. San Francisco: Jossey-Bass.

Berger, Peter L. and Thomas Luckmann. 1967. The social construction of reality: A treatise in the sociology of knowledge. New York: Anchor Books.

Biesta, G. 2019. Bildung and Erziehung: On the possibility of a distinction. A paper presented at the European Conference on Educational Research, as part of the symposium "Theorizing Education: A Dialogue among Curriculum Studies, Philosophy and Allgemeine Pädagogik" - Hamburg, Germany.

Carroll, Michael. 2006. Awake at work. Boulder: Shambhala.

Carroll, Michael. 2008. The mindful leader. Boulder: Shambhala.

Chaskalson, Michael and Megan Reitz. 2018. Mind time. London: Thorsons.

Chia, Robert. 2014. Reflections: In praise of silent transformation-Allowing change through 'letting happen' Journal of Change Management 14 (1): 8-27. https://doi.org/10.1080/14697017.2013.841006.

Coghlan, David and Teresa Brannick. 2001. Doing action research in your own organization. Thousand Oaks: Sage.

Dahl, Cortland, Christine D. Wilson-Mendenhall, and Richard J. Davidson. 2020. The plasticity of wellbeing: A training-based framework for the cultivation of human flourishing. PNAS: Proceedings of the National Academy of Sciences of the United States of America. https://doi.org/10.1073/pnas.20148 59117. 
Dewey, John. 1917. The need for a recovery of philosophy. In Creative intelligence: Essays in the pragmatic attitude, eds. John Dewey, A. W. Moore, H. C. Brown, G. H. Mead, B. H. Bode, H. W. Stuart, J. H. Tufts, and H. M. Kallen, 3-69. New York: Henry Holt and Company.

Fossella, Tina. Spring. 2011. Human nature, Buddha nature: An interview with John Welwood. Tricycle Magazine, https://tricycle.org/magazine/human-nature-buddha-nature/.

Fullan, Michael. 2006. Turnaround leadership. San Francisco: Jossey-Bass.

Fullan, Michael and Geoff Scot. 2009. Turnaround leadership for higher education. San Francisco: Jossey-Bass.

Goldmann, Lucien. 1959. Le dieu cache: Étude sur la vision tragique dans les "Pensées" de Pascal et dans le théâtre de Racine (Bibliothèque des Idées) (French Edition) (The hidden god). Paris: Gallimard.

Goldmann, Lucien. 1966. Sciences humaines et philosophie. Paris: Éditions Gonthier.

Goldman Schuyler, Kathryn. 2012. Inner peace-Global impact: Tibetan Buddhism, leadership, and work. Charlotte: Information Age Publishing.

Goldman Schuyler, Kathryn. 2016. Mindfulness as waking up: Musings about how to be optimally alive. Journal of Corporate Citizenship, 62, 59-75. https://doi.org/10.9774/GLEAF.4700.2016.ju.00010.

Goldman Schuyler, Kathryn, Susan Skjei, Jyotsna Sanzgiri, and Virpi Koskela. 2017. "Moments of waking up": A doorway to mindfulness and presence. Journal of Management Inquiry, 26, 86-100. https://doi. org/10.1177/1056492616665171.

Goldman Schuyler, Kathryn, Michelle Olsen Taylor, and Orit M. Wolberger. 2018. Bringing mindfulness and joy to work: Action research on organizational change. In Handbook of personal and organizational transformation, ed. Judith Neal, 1193-1216. Berlin: Springer.

Goodchild, Melanie, with Peter Senge, C. Otto Scharmer, Roronhiakewen (He Clears the Sky) Dan Longboat, Kahontakwas Diane Longboat, Rick Hill and Ka'nahsohon (A Feather Dipped in Paint) Kevin Deer. 2021. Relational systems thinking: That's how change is going to come, from our earth mother. Journal of Awareness Based System Change, 1, 75-103. ISSN 2767-6021. https://doi.org/10.47061/ jabsc.v1i1.577.

Heifetz, Ronald A., Alexander Grashow, and Marty Linsky. 2009. The practice of adaptive leadership: Tools and tactics for changing your organization and the world. Cambridge: Harvard Business Review Press.

Heifetz, Ronald A. 1994. Leadership without easy answers. Cambridge: Harvard University Press.

Kabat-Zinn, Jon. 2011. Some reflections on the origins of MBSR, skillful means, and the trouble with maps. Contemporary Buddhism 12: 1476-7953. https://doi.org/10.1080/14639947.2011.564844.

Kendi, Ibram X. 2019. How to be an antiracist. London: One World.

King, Elizabeth and Richard Badham. 2018. Leadership in uncertainty: The mindfulness solution. Organisational Dynamics.

King, Elizabeth and Richard Badham. 2020. The wheel of mindfulness: A generative framework for secondgeneration mindful leadership. Mindfulness 11 (1): 166-176.

Laszlo, Chris. 2019. Strengthening humanistic management. Humanistic Management Journal. https://doi. org/10.1007/s41463-019-00055-9.

Lawrence, Paul R., and Michael A. Pirson. 2015. Economistic and humanistic narratives of leadership in the age of globality: Toward a renewed Darwinian theory of leadership. Journal of Business Ethics 128: 383-394. https://doi.org/10.1007/s10551-014-2090-2.

Lesser, Marc. 2019. Seven practices of a mindful leader: Lessons from Google and a Zen monastery kitchen. Novato: New World Library.

Magee, Rhonda V. 2019. The inner work of social justice: Healing ourselves and transforming our communities through mindfulness. London: Penguin Random House.

Mannheim, Karl. 1936. Ideology and utopia: An introduction to the sociology of knowledge. San Diego: Harcourt.

Mannheim, Karl. 1952. Essays on the sociology of knowledge. Oxford: Oxford University Press.

Melé, Domènec. 2003. The challenge of humanistic management. Journal of Business Ethics 44 (1): 77-88.

McIntosh, Peggy. 1988. White privilege and male privilege: A personal account of coming to see correspondence through work in women's studies (Working Paper 189:1-20). Wellesley Center for Research on Women.

Mindful Nation, U. K. 2015. Report by the Mindfulness All-Party Parliamentary Group (MAPPG). https:// www.themindfulnessinitiative.org/Handlers/Download.ashx?IDMF=1af56392-4cf1-4550-bdd1-72e80 9fa627a.

Mingyur Rinpoche, Yongey. 2007. The joy of living: Unlocking the secret and science of happiness. New York: Harmony Books, Random House. 
Nelson, Melissa K. 2016. Native ecologies and cosmovisions of North America. In Routledge handbook of religion and ecology, ed. Willis Jenkins, Mary Evelyn Tucker, and John Grim, 138-147. Abingdon-onThames: Routledge.

Northouse, Peter G. 2016. Leadership: theory and practice. Seventh Edition. Thousand Oaks: SAGE Publications.

Pirson, Michael A. 2017. Humanistic management: Protecting dignity and promoting well-being. Cambridge: Cambridge University Press.

Pirson, Michael A. 2019. A humanistic perspective for management theory: Protecting dignity and promoting well-being. Journal of Business Ethics 159: 39-57. https://doi.org/10.1007/ s10551-017-3755-4.

Pirson, Michael A., and Paul R. Lawrence. 2010. Humanism in business - Towards a paradigm shift? Journal of Business Ethics, 93, 553-565. https://doi.org/10.1007/s10551-009-0239-1.

Purser, Ron. 2013. Beyond McMindfulness. https://www.huffpost.com/entry/beyond-mcmindfulness_b_ 3519289 Accessed 16 May 2021.

Purser, Ron E., Edwin Ng, and Zack Walsh. 2018. The promise and perils of corporate mindfulness. In Leadership Matters: Finding voice, connection and meaning in the 21st century, eds. Chris Mabey and David Knights, 47-62. Abingdon-on-Thames: Routledge.

Reason, Peter and Hilary Bradbury. 2008. Introduction. In The SAGE Handbook of Action Research: Participative inquiry and practice, eds. Peter Reason and Hilary Bradbury, 1-10. Thousand Oaks: Sage Publications.

Reitz, Megan, Lee Waller, Michael Chaskalson, Sharon Olivier, and Silke Rupprecht. 2020. Developing leaders through mindfulness practice. Journal of Management Development 39(2):223-239. https:// doi.org/10.1108/JMD-09-2018-0264.

Ritzer, George. 2004a. The McDonaldization of society (Revised New Century Edition). Pine Forge Press, Sage Publications.

Ritzer, George. 2004b. The globalization of nothing. Pine Forge Press, Sage Publications.

Ruiz, Don Miguel. 1997. The four agreements: A practical guide to personal freedom. San Rafael: Amber-Allen Pub.

Scharmer, C. Otto. 2009. Theory U: Leading from the future as it emerges. Oakland: Berrett-Koehler.

Scharmer, C. Otto. 2018. The essentials of Theory U: Core principles and applications. Oakland: Berrett-Koehler.

Schön, Donald A. 1990. Educating the reflective practitioner: Toward a new design for teaching and learning in the professions. Jossey-Bass.

Search Inside Yourself Leadership Institute. 2020. State of emotional intelligence report 2020.

Senge, Peter. 1990/2006. The fifth discipline: The art and practice of the learning organization. New York: Doubleday.

Senge, Peter O. 2012. "Leaders should be people who are deeply involved in their own realization of being a human being" - An interview with Peter Senge. In Inner peace-global impact: Tibetan Buddhism, leadership, and work, ed. Kathryn Goldman Schuyler, 317-32. Charlotte: Information Age Publishing.

Senge, Peter O., C. Otto Scharmer, Joseph Jaworski, and Betty Sue Flowers. 2005. Presence: Human purpose and the field of the future. New York: Currency, Doubleday, Random House.

Spiller, Chellie. 2021. 'I AM': Indigenous consciousness for authenticity and leadership. Leadership 17: 491-496. https://doi.org/10.1177/1742715021999590.

Spiller, Chellie, Michelle Evans, Kathryn Goldman Schuyler, and Lemuel M. Watson. 2021. What silence can teach us about race and leadership. Leadership 17(1), 81-98. https://doi.org/10.1177/ 1742715020976003.

Stroh, David Peter. 2020. Overcoming the systemic challenges of wealth inequality in the U.S. The Foundation Review 12 (4): 35-49. https://doi.org/10.9707/1944-5660.1541.

Swidler, Leonard. 2019. The "Golden Rule": The "Best Rule". Journal of Ecumenical Studies 54(2):279-288.

Tönnies, Ferdinand. 1887/2002. Community and society. (Tr. Charles P. Loomis). Garden City: Dover Publications.

Waddock, Sandra and Malcolm McIntosh. 2011. See change: Making the transition to a sustainable enterprise economy. Austin: Greenleaf Publishing.

Waddock, Sandra and Erica Steckler. 2009. Seeing the forest and the trees: Lessons from difference makers for sustaining themselves as they create institutional change. Presentation at the Academy of Management Annual Meeting, Chicago. 
Waddock, Sandra and Erica Steckler. 2013. Wisdom, spirituality, social entrepreneurs, and self-sustaining practices: What can we learn from difference makers? In The handbook of faith and spirituality in the workplace, ed. Judith Neal, 285-301. Springer.

Watson, Lemuel, W. In process. Illuminating a community of belonging: Indiana University Anti-Racism Agenda.

Wilson, Patricia A. 2016. The inner practice of community development: Embracing deep democracy in Mexico. In Creative social change: Leadership for a healthy world, eds. Kathryn Goldman Schuyler, John E Baugher, and Karin Jironet, 211-230. Bingley: Emerald.

Wilson, Patricia A. 2019. The heart of community engagement: Practitioner stories from across the globe. Abingdon-on-Thames: Routledge.

Wilson, Patricia A. 2021. Sensing the social field through action research: What's important, what's valid. Journal of Awareness Based Systems Change 1: 119-124.

Wolberger, Orit M. 2018. Change as becoming: An action research project. Doctoral Dissertation at Alliant International University.

Wolberger, Orit M., and Kathryn Goldman Schuyler. 2018. Leading change gently: Action research on workplace mindfulness. Unpublished paper presented at the Academy of Management Annual Meeting, Chicago.

Yukl, Gary and Rubina Mahsud. 2010. Why flexible and adaptive leadership is essential. Consulting Psychology Journal: Practice and Research 62 (2): 81-93. https://doi.org/10.1037/a0019835.

Publisher's Note Springer Nature remains neutral with regard to jurisdictional claims in published maps and institutional affiliations. 